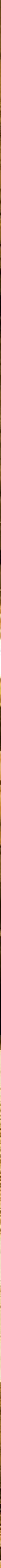




\section{Estruturas simbólicas e transmissão cultural: educação formal, mídia de massa e o debate da escola paralela}

Simbolic structures and cultural trasmission: formal education, mass midia and the paralel school debate.

DOI: $10.15213 /$ REDES.N12.P68

GABRIEL LYRA CHAVES Y DANIELA FAVARO GARROSSINI

\section{RESUMO}

Marshall McLuhan analisa a transição entre uma era 'letrada' e uma era 'eletrônica'. Este processo tem claras influências no campo da educação, principalmente após o surgimento dos mass media e da internet. O presente artigo busca observar este período de transição, e suas relações com o ferramental teórico de compreensão da realidade, a partir da separação entre pensamento discursivo e pensamento narrativo. Para tanto, dialoga com a comunicação educativa, levantando a questão da divisão entre ensino formal e escola paralela, e analisando esta separação a partir do tratamento da informação nos dois campos.

PALAVRAS CHAVE: ENSINO FORMAL, ESCOLA PARALELA, APRENDIZAGEM MÓVEL, PENSAMENTO NARRATIVO, PENSAMENTO DISCURSIVO 


\section{ABSTRACT}

Marshall McLuhan examine the transition between a 'literate' era and a 'electronic' one. This process has clear influence in education, specially after the emergence of mass media and internet. This article aims to observe this transition period, and its relations with the organization of theoretical tools to understand reality, as from the separation between discursive reasoning and narrative reasoning. Therefore, it dialogues with educational communication, raising the question of the division between formal and parallel school, and analyzing this separation from the scope of information treatment in both fields.

KEYWORDS: FORMAL EDUCATION, PARALLEL SCHOOL, MOBILE LEARNING, NARRATIVE REASONING, V

\section{INTRODUÇÃo}

Marshall McLuhan (1972), e toda uma escola de pensamento depois dele, apontam para as transformações sociais e cognitivas trazidas pela consolidação da imprensa enquanto veículo comunicacional no período que se segue à invenção de Gutenberg. Para o autor, este seria o principal elemento de ruptura entre o mundo moderno e a estrutura social medieval. McLuhan compara este processo à disseminação do uso da energia elétrica e seus refinamentos - representados pela eletrônica e pelas mass media $\neg-$, percebendo que estas novas ferramentas comunicacionais teriam colocado em movimento uma outra transformação social e mental, dinâmica na qual estaríamos mergulhados desde o princípio do século XX.

Quando confrontada com outras abordagens, caras às ciências sociais, a análise de McLuhan demonstra uma tendência reducionista, pois desvincula as TIC de seu contexto social e histórico, como se esta pertencesse a uma categoria externa à cultura. Apesar disso, se não observada como dogma, mas como discurso, a proposta do autor pode ser vista como mais uma contribuição para a análise da cisão entre as estruturas de pensamento medieval - oral, dogmático, icônico -, pensamento moderno - letrado, analítico, sequencial - e pensamento pós-moderno - imagético, rizomático e não-linear -, permitindo conexões com outras áreas do conhecimento e seus discursos sobre este fenômeno. Assim, também fará parte do escopo deste 
artigo analisar esta questão a partir de outras miradas, com o intuito de tecer um posicionamento crítico diante deste quadro complexo.

Como fruto desta cisão epistemológica e cognitiva entre moderno e pós-moderno, ressaltaremos que, no contexto da contemporaneidade, há uma lacuna entre os objetivos da estrutura formal de ensino e o seu papel na sociedade hiperconectada em que vivemos. Para além de se restringir ao apontamento desta lacuna, conhecida e vivenciada por qualquer docente, este artigo pretende levantá-la a partir da diferenciação entre pensamento discursivo e pensamento narrativo, fazendo a distinção entre ambos e observando como a separação entre eles foi distribuída, em termos de produção e transmissão cultural, ao longo das últimas décadas. A partir desta análise, fazemos alguns apontamentos para o tratamento de conteúdos dentro do contexto da aprendizagem móvel, ou m-learning.

\section{A COMUNICAÇÃo EdUCATIVA E A ESCOLA PARALELA}

Segundo Francisco Sierra (2014: 66-70), em A Galáxia de Gutenberg, Marshall McLuhan propõe a conhecida divisão entre meios quentes - servem o máximo de informação com o mínimo de participação, onde se encaixa a imprensa - e meios frios - transmitem um baixo nível de informação dentro de um contexto de alta participação, categoria onde se encaixa a televisão. Esta divisão influenciaria o uso do cérebro para a decodificação das mensagens: os meios quentes utilizariam mais o hemisfério esquerdo, responsável por atividades lineares, lógicas e/ou racionais, enquanto os meios frios seriam processados pelo hemisfério direito, de caráter simultâneo, holístico e sintético. Esta separação teria consequências diretas na forma de decodificação do mundo, direcionando também a organização social: o predomínio do hemisfério esquerdo nas sociedades letradas faz prevalecer a percepção analítica da realidade, ao passo que, nas comunidades de caráter mais tribal, a postura holística poderia ser atribuída à supremacia do hemisfério direito. Com a disseminação das telecomunicações e a partir do advento da televisão, estaríamos atravessando uma época de câmbio em nossa forma de perceber o mundo, deixando de lado uma abordagem estritamente analítica. McLuhan diz que esta seria a transição entre a Galáxia de Gutenberg e a Galáxia de Marconi.

Apesar de estas tendências terem sido apontadas em meados do século $\mathrm{XX}$, na segunda década do século XXI ainda observamos a estrutura escolar alheia ao processo, projetando e desenhando currículos de acordo com o 
projeto inicial de modernidade da Galáxia de Gutenberg, dentro da concepção ramista de "universalidade" do currículo escolar levantada e criticada por McLuhan (1972: 182-184). Mas esforços teóricos e metodológicos em direções diversas não são inéditos nem novos.

Francisco Sierra (2014: 35-44), ao fazer um levantamento sobre modelos teóricos e paradigmas da comunicação educativa, procede com uma dissecação cuidadosa e detalhada desta área de conhecimento. Para sustentar a argumentação que se constrói aqui, vamos nos deter nos três modelos metodológicos de comunicação educativa que o autor aponta, referenciando Mario Kaplún: 'o bancário, o dos efeitos e o dialógico ou transformador' (SIERRA, 2014: 36).

O modelo de educação bancária, predominante em nossa estrutura formal de ensino, estabelece que o processo educacional deve organizar os conteúdos de maneira planificada, sequencial e compartimentada, privilegiando a competição sobre a cooperação e o saber em detrimento do saber fazer. Não há fomento da capacidade crítica, e não há uma preocupação com a interdisciplinaridade. O educando, receptáculo vazio, deve ser educado pelo professor, o detentor do conhecimento que irá preenchê-lo. Quando concluído o processo, o educando, agora educado, deverá se mostrar capaz de recuperar as informações memorizadas, e não de refletir sobre elas.

O modelo dos efeitos, nascido da aplicação dos princípios da cibernética e das ciências da informação no campo da educação, se centrará em garantir o sucesso do processo comunicativo dentro da educação, com a transmissão fidedigna da mensagem. Neste sentido, "a aprendizagem é uma variável dependente do processo de transmissão e decodificação da informação" (Sierra, 2014: 42), apontando para a organização de programas de ensino centrados na máxima eficiência. Tanto o modelo dos efeitos quanto o bancário são extremamente centrados na primazia da informação, observando o processo educativo como movimento unidirecional - do professor para o aluno - e o conhecimento como razão pura, objetiva, dentro dos moldes positivistas.

O modelo dialógico ou transformador, proposto por Mario Kaplún com base nos estudos de Paulo Freire, é um modelo "centrado no processo, [que] concebe a educomunicação como um processo gerador de sentido. Favorece a apreensão da realidade antecipadora, participativa e contextualizada" (SIERRA, 2014: 39). Ao romper o caráter unidirecional da comunicação no processo educativo, permite que se observe o processo de geração de sentido como dialógico e participativo, recuperando também os aspectos colaborativo e crítico da aprendizagem. 
Em cada um destes modelos, os aspectos organizacionais da informação variam, o que resulta em diferentes abordagens para a sistematização da comunicação e para o tratamento de conteúdo. E, apesar da transição paradigmática que atravessamos, e da disponibilidade de abordagens diferenciadas, os tradicionais agentes socializadores, a família e a escola, ainda limitam à escola formal o papel de principal estrutura de transmissão de cultura. Ao mesmo tempo, a escola paralela - estrutura composta pelo conjunto dos meios de comunicação de massas -, livre de amarras formais, assume um papel muito mais ativo nesta transmissão, promovendo a educação informal de vastos setores de nossa sociedade.

Apesar de haverem iniciativas que incorporam tecnologias de informação e comunicação à estrutura formal de ensino, este movimento ainda é tímido, e esbarra constantemente na limitação imposta pela diferenciação entre docentes e discentes. O primeiro grupo, educado dentro do modelo bancário e alheio às possibilidades trazidas pelas tecnologias digitais, não compartilha a mesma forma mentis dos educandos, criados num contexto de hiperconexão. Com isso, as agendas dos dois grupos divergem em seus objetivos, dificultando o diálogo e colocando em xeque o sistema formal de ensino. A isso, ainda se soma a diferenciação entre pensamento discursivo e pensamento narrativo, mas guardaremos estas reflexões para um futuro próximo.

E se, para McLuhan, as redes de transmissão de rádio e televisão já teriam posto a esteira da transformação em movimento, é preciso levar em consideração que as TIC e o compartilhamento de informações proporcionado pelo ciberespaço, cada vez mais acessível, certamente estão acelerando este movimento e transformando em abismo a lacuna que se estabeleceu entre docentes e discentes em suas formas de decodificar o mundo.

Neste contexto, a comunicação educativa ou educomunicação se lança à reflexão sobre a relação complexa que se estabelece entre educação e comunicação. Como nos aponta Francisco Sierra (2014: 12), a UNEsCo, desde 1979, deposita grandes esperanças neste campo cultural estratégico, buscando guiar políticas internacionais que fomentem a educação através das TICs. Isto nos coloca de volta ao debate sobre a escola paralela, este 'conjunto de vias, mediante as quais, e à margem da escola, chegam até os alunos (e não alunos), as informações, os conhecimentos e certa formação cultural, correspondente aos mais variados campos' (PORCHER apud SIERRA, 2014: 55). Este debate levanta novas abordagens sobre os meios de comunicação e seu papel na formação cultural e na nova educação. A repulsa inicial, que costumava demonizar as novas tecnologias como corruptoras da ordem social, passa a ser gradualmente substituída por estratégias de incorporação destas novas 
ferramentas, na busca de uma educação “ 'com', 'através' e 'dos' meios, com a finalidade de adaptar os conhecimentos de uma nova sociedade dominada pela hiperinflação 'de massas e midiática' ”' (SIERRA, 2014: 12).

Este processo, em construção por mais de 35 anos, certamente não foi harmônico, e atravessou vários problemas de abordagem, teoria e metodologia. Por questões de escopo deste ensaio, consideraremos apenas que o referido processo conduziu à consolidação das políticas direcionadas à Aprendizagem Móvel (ou Mobile Learning), conforme expostas pela unesco. O termo é definido como 'o uso de tecnologias móveis, isoladamente ou em combinação com outras tecnologias de informação e comunicação (TIC), a fim de permitir a aprendizagem a qualquer hora e em qualquer lugar' (UNESCO, 2014(1): 7). E esta definição reverbera nas recomendações propostas pela UNESCO aO BRICS - agrupamento de nações emergentes composto por Brasil, Rússia, Índia, China e África do Sul - para construir a educação do futuro, objetivando o fortalecimento dos sistemas educacionais, a excelência no ensino superior, o desenvolvimento de habilidades para o crescimento (voltadas para atividades práticas de mercado) e o apoio à educação em outros países em desenvolvimento (UnEsCo, 2014(2): 2-4). Percebe-se, neste conjunto, o desejo de estabelecer uma educação inclusiva, aberta para todos, buscando contornar limitações em áreas de fragilidade social, atingidas por desastres naturais ou por conflitos armados, e atuando como uma ferramenta de desenvolvimento social.

\section{OUTRAS GaLÁxias POSSíveis}

Até este ponto, optamos por restringir o campo de análise das transformações sociais impulsionadas pela tecnologia à proposta de McLuhan. Conforme mencionado anteriormente, esta proposta é passível de críticas, como nos lembra Francisco Sierra (2014: 59-66). McLuhan desvincula as tecnologias e seu desenvolvimento do contexto histórico e social de onde emergem. Assim, retira do processo histórico sua autonomia, submetendo-o a esta força externa, superior e autônoma: a tecnologia. Neste sentido, ele a emancipa, tornando-a capaz de definir toda a articulação social e mental dos humanos, sujeitando-os. Antes de ser independente, toda tecnologia, técnica e/ou articulação mental é uma manifestação da cultura, não podendo estar externa a esta. É fundamental levar isto em consideração, principalmente quando nos adentramos nos campos da ciência da informação, da cibernética e da tecnologia. Assim, também aproveitaremos para trazer outras 
possibilidades de análise do contexto que McLuhan irá definir como a transição entre a Galáxia de Gutenberg e a Galáxia de Marconi.

\subsection{A ESCALADA DA ABSTRAÇÃo}

No ensaio A filosofia da caixa preta, Vilém Flusser (1985) separa a empreitada humana em três grandes períodos: a pré-história, história e pós-história. A pré-história seria o período da tradição oral, da representação pictórica e do tempo circular (ou mágico). As representações imagéticas do mundo implicavam em abstrações de algumas das dimensões da realidade. Afinal, um desenho sobre uma superfície abstrai, necessariamente, as dimensões físicas da profundidade e do tempo. Para compreender um desenho, é necessário desenvolver a imaginação, que seria a capacidade de abstrair e reconstruir essas dimensões "manipuladas", de modo extrair sentido de uma imagem. Mas, numa imagem, o tempo abstraído pode ser reconstruído de diferentes maneiras, à medida que o olhar caminha entre seus elementos composicionais. O tempo não é mais linear, como o é na realidade física: no campo da imagem, o tempo pode avançar, voltar, fazer saltos. É um tempo mágico e cíclico, diretamente relacionado aos ciclos sazonais da natureza.

A história, fruto da escrita e berço do pensamento linear, introduz uma nova forma de abstração da realidade: o texto. Derivado de imagens, o texto surgiria de um novo passo em direção à abstração, sendo a decomposição de um elemento bidimensional, a imagem, em outro unidimensional, o texto linear. Três das quatro dimensões da realidade objetiva seriam abstraídas e decodificadas em um novo tipo de código simbólico, dominado por escribas, sacerdotes e alguns membros da elite. E, neste contexto, a pré-história e a história teriam convivido até o advento da imprensa, resultando no letramento das massas que, de acordo com Flusser, passam a acessar um "pensamento conceitual barato", em oposição ao "pensamento conceitual hermético" dos círculos científicos elitistas.

Finalmente, entraríamos na pós-história, marcada pelo domínio da imagem técnica e de um novo tempo circular. Nas palavras do autor, '[h]istoricamente, as imagens tradicionais são pré-históricas; as imagens técnicas são pós-históricas. Ontologicamente, as imagens tradicionais imaginam o mundo; as imagens técnicas imaginam textos que concebem imagens que imaginam o mundo.' (FLUSSER, 1985: 10).

Mas, para compreender a imagem técnica, é necessário recorrer à definição de aparelho, que seria uma nova categoria de ferramenta pós-industrial, 
representando não instrumentos de interação e transformação da realidade, mas sim aparatos de produzir informação. Apesar de construídos industrialmente, os aparelhos adotam uma lógica pós-histórica ao romper o ciclo de trabalho como alteração da realidade. Assim a informação, fruto do trabalho com o aparelho, amplia o grau de afastamento entre homem e realidade. Aparelhos também são frutos de textos científicos interrelacionados.

As imagens técnicas, frutos dos aparelhos, não são abstrações da realidade, como o são as imagens tradicionais. São, como vimos, a representação gráfica de conjuntos de textos científicos que abstraem a realidade. Por serem muito semelhantes ao que vemos, parecem mais próximas da realidade do que uma imagem tradicional, o que induz ao engano amplamente difundido de que são "retratos" da realidade e de seus fenômenos. Mas, para que sejam possíveis, implicam na articulação cada vez mais complexa entre teorias científicas diversas.

Um exemplo simples e que faz parte do cotidiano de muitas pessoas é o momento de digitação de um texto. Observa-se o teclado, em sua existência física, e na tela de um aparelho a representação de uma folha de papel. Aparentemente, a situação é tão simples quanto a mecânica da máquina de escrever. Pressiona-se uma tecla e vê-se o resultado "na folha de papel". A realidade do evento, contudo, é bem diferente. Para que isso seja possível, é necessário que se articulem uma infinidade de textos científicos, como teorias da cibernética, da ciência da computação, da microeletrônica e do design de informação e interação, para ficar em poucos exemplos. A distância que a 'letra' percorre entre o pressionar e o visualizar é infinitamente mais complexa do que a distância física percorrida pela letra no sistema mecânico da máquina de escrever.

O mesmo ocorre com qualquer outra imagem técnica, seja ela a fotografia analógica, a imagem televisionada ou a torrente digital de textos, imagens e vídeos que flui, espessa, pelo ciberespaço. Assim, a transição GutenbergMarconi de McLuhan poderia representar este movimento em que a modernidade, com os processos paralelos de imprensa, industrialização e produção científica, teria instaurado mais um grau de separação entre nós e a realidade do mundo. $\mathrm{E}$ isso abre espaço para mais uma reflexão.

\subsection{EDUCAÇÃO, ORDEM E CONTRADIÇÃo}

Quando discute a consolidação da modernidade na obra Ensaios sobre o conceito de cultura, Zigmunt Bauman (2012: 07-69) procura observar o papel da 
educação dentro deste processo. Em linhas gerais, com a dissolução da ordem social medieval, a nova elite burguesa se depara com um vácuo social, que precisa ser preenchido com uma nova proposta agregadora. Duas instâncias desta nova sociedade se estruturam sob este projeto: o sistema jurídico em um campo, o técnico e científico orientados pelo humanismo em outro. Enquanto o sistema jurídico ajuda a preencher o possível vazio deixado pela ruptura com as regras de conduta moral características do cristianismo, estabelecendo os novos padrões de comportamento social e trabalhando para manter a ordem e o progresso dos novos Estados, a produção tecno-científica se encarrega de ressignificar o mundo simbólico, adotando novos procedimentos para explicar a realidade objetiva do mundo à luz do pensamento discursivo.

E, para que esta nova ordem social fosse introjetada nas "massas", o sistema educacional foi fundamental. Assim, além de sedimentar a nova elite instruída na posição de mando, o projeto iluminista estabeleceu "o resto da sociedade como objeto natural de seus ensinamentos, de sua ação de ensino, de 'cultivo', e assim reproduziu a estrutura de dominação na sua nova forma, a moderna" (Bauman, 2012: 50). O ensino formal, portanto, é a ferramenta fundamental do processo civilizatório de domesticação das massas, e é neste contexto que ele ganha a importância social e política que ainda hoje lhe são dadas, apesar dos pesares e insucessos do projeto.

Estruturado sobre um processo dualista - e, em vários aspectos, maniqueísta -, o projeto iluminista de modernidade tratou de polarizar em termos opositivos aspectos da realidade que antes eram complementares. A título de exemplo, os aspectos objetivo e subjetivo da personalidade foram separados hierarquicamente, um dos motivos para que as "ciências da natureza" ocupem, mesmo hoje, um papel de destaque frente às "ciências humanas" ou às "artes", ou para que o pensamento discursivo seja priorizado em detrimento do pensamento narrativo, conforme veremos mais à frente. Neste processo de dissecação e reconstrução da realidade objetiva, o projeto iluminista também tratou de permitir que argumentos contraditórios pudessem ser articulados harmonicamente na definição de suas pautas, como ocorre na definição de liberdade. Como bem destaca Bauman,

A liberdade é uma relação social: para que alguns sejam livres a fim de atingir seus objetivos, outros devem ser não livres no que se refere a opor resistência aos princípios. A liberdade de uma pessoa pode ser desconcertante, já que está impregnada do risco de erro. Mas a liberdade dos outros parece, à primeira vista, um obstáculo perigoso à liberdade de ação de uma pessoa. 
Ainda que a liberdade de alguém possa ser contemplada como uma bênção indubitável, a perspectiva de liberdade ilimitada para todos os outros poucas vezes é agradável. Mesmo para os mais ardentes entusiastas da autodeterminação humana, a noção de 'restrições necessárias' dificilmente foi algo estranho. (BAUMAN, 2012: 15).

Edgar Morin (1998) também irá se debruçar sobre as ambiguidades do paradigma da modernidade. Como ele ressalta, duas vanguardas distintas da Física, a mais clássica das ciências naturais, abrirão caminho para o processo de questionamento dos limites da lógica dedutivo-identitária que estruturou todo o projeto iluminista: a teoria da relatividade, proposta por Albert Einstein, de maneira mais tímida, e de maneira mais contundente nos estudos de Werner Heisenberg, no campo da física quântica. Nos dois contextos, as leis newtonianas apresentam distorções ou mesmo se mostram impraticáveis. Isso põe em xeque todo o cabedal teórico da mais exata das ciências e, principalmente, expõe as limitações da lógica que estrutura o pensamento moderno. No contexto deste artigo, nos basta compreender que esta crise teórica serviu para que o pensamento cientificista passasse por uma série de revisões e análises, deixando de ocupar a categoria de verdade e abrindo caminho para que os movimentos estruturalista e pós-estruturalista o situassem como mais uma forma de discurso, movimento que instaura - ou indica o caminhar para - a pós-modernidade. Aqui, como em Flusser, a transição mcluhiana Gutenberg-Marconi apresenta uma outra roupagem, com outros motivos, consequência e estrutura. E, com este breve passeio teórico, esperamos ter demonstrado outras possíveis articulações para o processo de transição de galáxias em McLuhan, demonstrando a complexidade da situação e a necessidade de conhecer outras abordagens.

\section{NARRATIVA, PENSAMENTO DISCURSIVO E PENSAMENTO NARRATIVO}

Resgatando o trabalho de Tzvetan Todorov, Vera Lúcia Menezes de Oliveira e Paiva (2008: 261) nos lembra que uma narrativa ideal nos apresenta uma situação estável, perturbada por uma força externa. Ao longo de uma série de acontecimentos, o equilíbrio é reestabelecido, criando uma situação análoga à inicial, mas distinta devido às mudanças geradas na busca do equilíbrio. Outros teóricos, como Christopher Vogler (2006) e Joseph Campbell (1995) antes dele, chegam a estabelecer uma estrutura arquetípica 
para esta jornada de busca, definindo algumas características comuns à maioria das narrativas humanas, dentro e fora da tradição ocidental. Mas, antes de nos restringirmos aos aspectos formais que definem e identificam a narrativa clássica, compartilhamos com Paiva o desejo de compreender os tipos particulares de sentido e significação que podem ser construídos dentro de uma estrutura narrativa, e como estes se diferenciam da definição clássica de ciência diretamente relacionada ao pensamento discursivo. E, neste sentido, abriremos diálogo com outros teóricos que também se debruçam sobre estas questões.

Como nos aponta Bruner Jerome (1991) em A construção narrativa da realidade, a história da ciência no ocidente teve como projeto a busca de uma "verdade" objetiva, factual, impregnada nos eventos, externa e independente de seu observador: o conhecimento - posteriormente, o conhecimento científico. Para atingi-la, se consolidaram dois caminhos possíveis: o empirismo, focado no contato dos sentidos com o mundo externo da natureza, e o racionalismo, fundamentado no poder da razão como ferramenta de dissecação da realidade. Um prioriza a natureza. O outro, o observador. Mas, nos dois casos, a ferramenta para a aquisição do conhecimento seria o pensamento discursivo, priorizado enquanto forma mais pura de organização mental. Para muitos, a única possível no caminho da construção científica. Cria-se, neste contexto, a metáfora da luz para a ciência e o pensamento racional, que teria a função de afastar as supostas trevas de uma era dominada por crenças, dogmas e estagnação. Como vimos, este processo se autodenominou Iluminismo, e teve consequências diretas sobre a estruturação do sistema de ensino, perpetuando a hegemonia do pensamento discursivo e treinando as crianças para que sejam pequenos cientistas, pequenos lógicos, pequenos matemáticos (Bruner, 1991: 04). O foco empiricista - e, muitas vezes, positivista - da abordagem educacional tradicional se coloca à margem da construção de relações simbólicas de outra ordem: as interpessoais e, num sentido mais amplo, as sociais, e mesmo as de auto-representação.

Em contraposição a esta forma de organização mental, Bruner ressalta a dinâmica do pensamento narrativo:

Como os domínios da construção lógico-científica da realidade, [o domínio narrativo] é bem apoiado por princípios e procedimentos. Ele possui um ferramental cultural ou tradicional disponível, sobre o qual seus procedimentos são modelados. (...) Sua forma é tão familiar e ubíqua que ele tende a passar desapercebido, de forma semelhante à nossa suposição 
de que o peixe seria o último a descobrir a existência da água. Como eu argumentei extensamente em outros lugares, nós organizamos nossa experiência e nossas memórias sobre os acontecimentos humanos predominantemente sob a forma narrativa - estórias, desculpas, mitos, razões para fazer ou não fazer, e daí em diante. Narrativa é uma forma convencional, transmitida culturalmente, cujo uso se vê restrito apenas pelo domínio individual que cada um tem de suas formas (...).(BRUNER, 1991: 04)

De acordo com Sarah Worth (2007), o pensamento discursivo é capaz de abarcar duas grandes proposições: "saber que" e "saber porque", caminhos para uma abordagem objetiva da realidade. Os resultados práticos desta abordagem são inquestionáveis, e beneficiaram o mundo moderno/pós-moderno com o desenvolvimento tecnológico em suas mais variadas facetas. Contudo, a abordagem objetiva deixa de lado aspectos fundamentais da realidade social. O pensamento narrativo, de organização distinta, permite acesso ao "saber como seria”, abrindo caminho para a identificação empática. Isso porque, enquanto o pensamento discursivo se debruça sobre princípios como coerência, verificabilidade e não-contradição, o pensamento narrativo parte em busca da verossimilhança, operando num nível interno de ordenamento e priorizando fazer sentido em detrimento de ser verificável. Isso coloca a estrutura narrativa mais próxima da forma como nos percebemos enquanto presença no mundo, e do modo como organizamos nossas experiências na esfera psicológica.

No artigo A vida como narrativa, Jerome Bruner (2004) defende que o pensamento narrativo seria a ferramenta pela qual maioria dos humanos extrai sentido de suas experiências ao longo da vida. Quando olhamos para nossas experiências e procuramos organizá-la, o mais natural é que o façamos com base em um enredo autocentrado. Neste contexto, elementos diferentes e não relacionados são, muitas vezes, observados a partir de uma relação causal, dentro de parâmetros aceitáveis em termos de verossimilhança, mas não comprováveis em termos de verificabilidade. O próprio autor aponta este como um dos principais problemas do exercício autobiográfico: quem relata tende a criar uma lógica discursiva sobre sua própria vida. Ao rememorar, a sequência aleatória de eventos que compõe sua experiência é organizada, e elos ficcionais são usados para criar uma malha de sentido. Elos narrativos.

Durante este processo de autoconstrução, a posição que o narrador assume tem muito a dizer sobre as características psicológicas de um 
indivíduo. Em linhas gerais, através de uma relação que se estabelece entre a escolha dos verbos (passivos ou ativos) e a forma de se posicionar frente aos acontecimentos, seria possível compreender como uma pessoa percebe a si mesma, e que tipo de imagem mental constrói sobre sua relação com o mundo. Essas imagens estão muito próximas à estrutura geral das fábulas, o que talvez justifique a facilidade que temos para imergir nessas estruturas narrativas, abordagem que permitiria uma aproximação com o conceito de arquétipo de Carl Jung.

Em um cenário mais amplo, a organização das memórias está mais próxima de um processo de "contação de história" do que de uma estrutura discursiva, o que situa o pensamento narrativo como elemento central em dois processos complementares: stricto sensu, na construção e organização do "eu", através da conferência de sentido às nossas experiências; e lato sensu, na consolidação do conceito de indivíduo e no papel que este conceito assume em nossa organização social. E, em termos práticos, recorrer à estrutura narrativa facilita a criação de uma aproximação empática com qualquer interlocutor.

\section{ALGUMAS CONSIDERAÇÕES}

$\mathrm{Na}$ consolidação do projeto iluminista, se estabelece uma antinomia entre pensamento narrativo e pensamento discursivo, evento que pode ser analisado como um indício - ou sintoma - do aspecto disjuntivo do paradigma da modernidade, conforme apontamos em Edgar Morin (1998). Este divórcio, principalmente a partir do século XX, relegou a guarda da estrutura de pensamento discursivo ao ensino formal, enquanto gradualmente a escola paralela tomou para si a estrutura narrativa de pensamento, com informação baseada em enredo predominando de maneira hegemônica na grade de programação de redes de televisão, no fluxo de tráfego - legal e ilegal - de dados pelo ciberespaço, ou na própria gestão compartilhada das narrativas pessoais proposta pelas redes sociais digitais.

$\mathrm{O}$ incremento deste movimento, conduzido pela mídia de massa no contexto da escola paralela, pode ser percebido na maior utilização de estruturas narrativas de enredo para organizar conteúdos. Anteriormente mais objetivas, hoje as notícias veiculadas se apoiam na exposição de um contexto normal, na apresentação de uma força de desequilíbrio e na busca por se recuperar este equilíbrio, estando muito mais próximas da organização narrativa do que da discursiva. Muito presente na linguagem dos jornais e, 
principalmente, telejornais esportivos, esta tendência tem permeado grande parte da esfera jornalística atual. Analisemos o trecho abaixo:

Apesar da melhora significativa a cada jogo com a camisa do Corinthians, o atacante Vagner Love admite o incômodo com a falta de um gol pelo seu novo clube. No empate sem gols com o RB Brasil, neste sábado, na arena corintiana, Love teve as duas melhores chances do time no segundo tempo - ambas levaram perigo, mas não resultaram em gol (veja nos vídeos). Ele sentiu que está próximo de marcar.

Na partida passada, contra o São Bernardo, o atacante já tinha atuado bem. Além de criar boas chances, foi dele a assistência para Malcom fazer 1 a o - resultado final do duelo. (Globoesporte, 2015)

Neste caso específico, o contexto normal seria a recente atuação de Vagner Love no novo time, enquanto a falta de gols marcaria a força de desequilíbrio, o conflito do enredo. Apesar da presença do conflito, o jogador - ou herói - já se sente próximo de marcar e tem criado boas chances, o que aponta para a superação do desequilíbrio e para a conclusão do ciclo narrativo. Num passado não muito distante, isso teria sido resumido a um texto curto e objetivo, como "Vagner Love continua sem marcar pelo Corinthians", transmitindo a mesma quantidade essencial de informação, mas criando um nível limitado de empatia.

A mesma estratégia perpassa a produção de conteúdo em vários setores de nossa imprensa e, neste processo, a articulação dos elementos passa a ter compromisso menor com a realidade verificável, e maior com a coerência interna da narrativa, amplificando o caráter ideológico do discurso e diminuindo o informacional. A adoção desta estrutura facilita a comunicação com a população não letrada, não excluindo a letrada, o que coloca a escola paralela em enorme vantagem comunicativa, quando comparada ao ensino formal.

O que depreendemos desta análise é que, para além de incorporar o uso das TICs nas estratégias educativas, o sistema educacional poderia agregar o potencial imersivo das narrativas para organizar e adaptar seus conteúdos, criando pontes de comunicação mais eficientes com os educandos. Este é o ponto de partida de uma pesquisa mais ampla, que pretende estruturar uma metodologia de tratamento de conteúdo para ambientes de aprendizagem móvel. Esta metodologia apoia-se no uso das narrativas e do pensamento narrativo para, gradualmente, ampliar a compreensão do pensamento discursivo e de seus aspectos específicos. 
ESTRUTURAS SIMBÓLICAS E TRANSMISSÃO CULTURAL: EDUCAÇÃO FORMAL, MÍDIA DE MASSA E O DEBATE DA ESCOLA PARALELA

\section{REFERENCIAS BIBLIOGRÁFICAS}

BAUMAN, ZIGMUNT. Ensaios sobre o conceito de cultura. Tradução de Carlos Alberto Medeiros. Rio de Janeiro: Zahar, 2012.

BRUNER, JEROME. Life as narrative. In: Social Research: An International Quarterly, Vol. 71, Issue 3, p. 691-710, 2004.

BRUNER, JEROME. The narrative construction of reality. In: Critical Inquiry. Vol. 18, p. 1-21. Chicago: Chicago Jornals, 1991.

CAMPBELL, JOSEPH. O herói de mil faces. São Paulo: Editora Pensamento, 1995.

FLUSSER, VILÉM. A filosofia da caixa preta: ensaios para uma futura filosofia da fotografia. São Paulo: Hucitec, 1985.

FREIRE, PAULO. A pedagogia do oprimido. Rio de Janeiro: Paz e Terra, 1974.

GLOBOESPORTE, 2015. Vagner Love se vê perto de primeiro gol, mas lamenta:

"Fico na pilha". In: Globoesporte <http://globoesporte.globo.com/futebol/ times/corinthians/noticia/2015/03/vagner-love-se-ve-perto-de-primeiro-gol-mas-lamenta-fico-na-pilha.html>, 15/03/2015.

HALL, STUART. A identidade cultural na pós-modernidade. Tradução de Tomaz Tadeu da Silva \& Guacira Lopes Louro. Rio de Janeiro: DP\&A, 2001.

KAPLÚN, MÁRIO. Una pedagogia de la comunicación (el comunicador popular). La Habana: Editorial Caminos , 2002.

MCLUHAN, MARSHALL. A Galáxia de Gutenberg: a formação do homem tipográfico. Tradução de Leônidas Gontijo de Carvalho e Anísio Teixeira. São Paulo: Editora Nacional/Editora da USP, 1972.

MORIN, EDGAR. O método 4: habitat, vida, costumes, organização. Tradução de Juremir Machado da Silva. Porto Alegre: Sulina, 1998.

PAIVA, VERA LÚCIA MENEZES DE OLIVEIRA E. A pesquisa narrativa: uma introdução. Revista Brasileira de Linguística Aplicada. [online]. 2008, vol.8, n.2 [citado 2015-01-12], pp. 261-266 . Disponível em: $\quad<$ http://www.scielo.br/scielo.php?script=sci_arttext\&pi$\mathrm{d}=\mathrm{S} 1984-63982008000200001 \& \operatorname{lng}=e s \& n r m=i s o>$. ISSN 1984-6398. http:// dx.doi.org/10.1590/S1984-63982008000200001.

SIERRA, FRANCISCO. Introdução à teoria da comunicação educativa. Tradução de Daniela Garrossini \& Flávia Beatriz Werneck. Brasília: Verbena, 2014.

SOUSA, JOÃO. De Gutenberg para Marconi: hiper-texto e hiper-ficção. Lisboa: Instituto Universitário de Lisboa, 1998. Disponível em < http://semiotica. com.sapo.pt/artigos/guttenber-para-marconi.pdf $>$, acesso em 18/02/2015.

UNESCO 2014 (1). Diretrizes de políticas para a aprendizagem móvel. In: Sobre a Unesco no Brasil <http://www.unesco.org/new/pt/brasilia/about-this-of- 
fice/single-view/news/diretrizes_de_politicas_da_unesco_para_a_aprendizagem_movel_pdf_only/\#.VQS8qhDF95A>, 05/11/2014.

UNESCO 2014 (2). BRICS: construir a educação para o futuro; prioridades para o desenvolvimento nacional e a cooperação internacional. In: Sobre a Unesco no Brasil < http://www.unesco.org/new/pt/brasilia/about-this-office/single-view/news/brics_building_education_for_the_future_priorities_for_national_development_and_international_cooperation/\#. VQS9gxDF95B>, 05/11/2014.

VOGLER, CHRISTOPHER. A jornada do escritor : estruturas míticas para escritores. Tradução de Ana Maria Machado. Rio de Janeiro: Nova Fronteira, 2006.

WORTH, SARAH. Narrative knowledge: knowing through storytelling. Disponivel em < http://web.mit.edu/comm-forum/mit4/papers/worth.pdf>, acesso em 09/01/2015. 
ESTRUTURAS SIMBÓLICAS E TRANSMISSÃO CULTURAL: EDUCAÇÃO FORMAL, MÍDIA DE MASSA E O DEBATE DA ESCOLA PARALELA 